\title{
XXXV. Observations upon the disease, in sheep, called in England foot-rot
}

\section{Charles Pictet}

To cite this article: M. Charles Pictet (1806) XXXV. Observations upon the disease, in sheep, called in England foot-rot , Philosophical Magazine Series 1, 25:99, 227-236, DOI: $10.1080 / 14786440608563438$

To link to this article: http://dx.doi.org/10.1080/14786440608563438

曲 Published online: 18 May 2009.

Submit your article to this journal $\sqsubset \pi$

Џ Article views: 2

Q View related articles $\sqsubset$ 


\section{[ 227 ]}

XXXV. Olservations upon the Disease, in Sheep, called in England Foot-rot. By M. Chardes Pictet, of Geneva*.

I THINK I shall render a service to the proprietors of sheep by calling their attention to a malady which, to my knowledge, has not been described by the veterinarists of any country, ard which, to the present moment, appears to have been unknown in Francet. The following is the occasion upon which I observed it:

In the month of May 1804, I received from Piedmont a flock of 200 sheep of various mongrel breeds of the second and thircl generations. The animals came to hand in good condition, but some of them were lame. The flock was placed, with a hundred other mongrels, on a flat mountain, the pasturage of which is healthy and of good quality. We did not pay very great attention to the lame sbeep, because in general, upon a journey, they cripple often from fatigue alone, and their lameness goes off after resting a while. I never yet received a lot of Spanish sheep among which there was not a few lame ones at their arrival; but this defect was never of long continuance.

In the present case, however, the lame animals became worse and worse, and every day others of them began to grow lame, while none of the others grew any better. Not suspecting any contagion, we attributed this affection to the rocky nature of the pasturage; to the frequent journeys which the sheep took from a rivulet to go and feed; and also to the circumstance that the sheep-cot was not frequently enough renewed. We took precautions against all these various causes, and yet the malady continued among the sheep. At the end of six weeks every one among them was lame; and some of them were affected in all their four legs. They crawled upon their knees while feeding, and the worst of them, fell off very much in their appearance. It now

* From Bit. Brit. vol. x. p. 371.

+ The Pietin, or Pietine, or the Fourchet, which Carlier and others have mentioned, is a slight malady, not contagious, and wholly different from that which I am about to describe. 
became indispensably necessary to assist this flock by every means in our power. We removed them to the distance of six leagues; their removal was not effected without great trouble, and was very tedious : we also had recourse to carriages for conveying the most diseased among them; but in spite of all our care, many fell a victim to the disease, unable to bear the fatigue.

The different individuals of the flock presented all the varieties of the disease; which may be reduced to three principal ones. The animals in the first stage of the disease were only a little lame, appeared without fever, and preserved their appetite. Upon inspecting the foot, there was only a slight redness discovered at the root of the hoofs, or a slight oozing out of matter round the hoof; sometimes only a slight degree of heat in the lame foot, without any apparent irritation.

The sheep which had the malady in the second degree were lame all fours, had a fever, appeared dull, fed slowly, and were often on their knees if the fore-legs were attacked. Upon inspecting the foot, there was an ulceration, as well at the root of the division of the hoofs, as at the juncture of the horn to the leg, accompanied by a whitish and fetid sanies.

Such animals as were in the third degree of the disease had a continual fever; they were meagre and sorrow ful, rose up with difficulty, and lost their wool. The ulceration of the feet was venomous, and resembled a white gangrene. Purulent collections were formed under the hoof, and made their appearance at the junction of the horn and the skin. Among some sheep the hoof was detached or entirely destroyed, and the flesh of the two divisions of the foot was one complete ulcer. In others the hoof had kept on ; because the flowing of the purulent matter made its appearance at the sole, and had gnawed and completely destroyed it. In this case, the interior of the foot, upon tuming it up to look at it, offered only a putrid mass filled with worms, contained in the horn of the hoof; the flesh and the ligaments appeared completely destroyed, and the bones of the feet were carious; the smell was cadaverous and insupportable. 
We endeavoured at first to classify and separate the animals according to the stage of the disease. The antiseptic lotions, such as red wine, 'vinegar, extract of bark, and oak bark, were employed; as also fumigations of nitric acid, to weaken the putrid tendency, and second the effect of the remedies.

I heard from Piedmont, that the vitriol of copper in powder, as a drying caustic, was very useful at the commencement of the disorder in checking its progress. We employed it, as well as martial vitriol, without any remarkable success, upon such animals as were only slightly attacked. It is probable that the contagious influence, which we had not yet learnt to guard against sufficiently, had destroyed the effect of this remedy.

The acetite of lead or saturnine extract was employed with more advantage. Antimonial beer was useful in drying the wound, and the lapis infernalis in burning the bad flesh, which was speedily reproduced after the incisions which accompanied the complete cleaning of the feet.

The treatment of a numerous flock in this miserable situation is extremely perplexing. Four shepherds and several assistants were employed in taking care of the 300 lame sheep, and it was an extremely disagreeable business for all of them. The animals were examined every day one by one, and such of them as were unable to go to pasture were fed in the sheep-cot, where the forage was carefully spread out for them ; because the sick animals had neither strength nor inclination to pull it out of the racks : it was necessary to renew the litter often, and to perfume the sheep-cot several times a-day; a precaution which prevented the smell from becoming insupportable to those who dressed the sores.

This was not all. The lambs made their appearance before we had overcome the disease; several of the poor sheep miscarried, or produced lambs which were so weakly that they could not live; others of the lambs died for want of milk, and those which survived took the disease; all which increased our difficulties.

The disease raged with all its violence for three months, 
and during a whole year many of the animals continued lame. If we calculate the loss of the animals which died of the disease, the loss of the lambs, and the great expenses attending so tedious a cure, we may be convinced that the scab itself, terrible as it is, is a less troublesome malady than the foot-rot when it is contagious and general in a flock.

Before pointing out the method of preventing and curing this evil, I shall mention a fact which will show how far it is contagious, and of how much consequence it is to incrcase our precautions in order to get rid of it. The rams who were upon the mountain at the same time with the diseased flock, took the foot-rot. They were separated from the rest of the diseased animals; and at the end of four months, after having passed through all the usual operations, they appeared to be cured. They still had tender feet, however, and walked with pain; but as the hoof was well recovered, and there was no appearance of ulceration upon it, they were driven to the neighbourhood of a Spanish flock. They were placed under a pent-house, separated from the sheepcot by a wall. Some of these rams continued to eat out of the rack upon their knees, which we attributed to the sole of the foot not being yet consolidated; but at the end of fifteen days we perceived that an oozing out of purulent matter had again commenced at the juncture of the horn of the hoof. They were then transported ints an infirmary, to be submitted once more to the same treatment. The straw upon which they had lain was not taken away; and the Spanish flock having afterwards been sent into this penthouse, the foot-rot began to show itself among them in about fiftcen days. The vigorous measures and precautions I followed, and the treatment I am about to recommend, hindered the disease from proceeding any further in this Hock than the second degree; otherwise I do not believe that a single beast would have escaped.

\section{Precautions and Treatment.}

At all times, upon receiving a strange flock, it is advisable to kcep them separated until it is well ascertained that 
they are not infected with the scab or any other contagious disorder.

The precaution is not less proper in the case of the footrot; for although there may be no crippled animal in a flock newly come to hand, yet there may be one among them which had been imperfectly cured during the journey, and in which the disease may break out anew. If there are any actually lame at their arrival, they must be carefully examined. Sometimes it happens that they may chance to be crippled from some other cause than that of foot-rot. On a journey in a moist season the clay sometimes gets hard between the hoofs, and thereby lames the animal. A single glance will suffice to see whether this is the cause of the lameness. Sometimes they are crippled in consequence of the gland between the hoofs being swelled: this is cured of itself, or at the worst by cutting off the gland, and it is not contagious. At other times the animal is crippled merely from fatigue; for which a little rest is the obvious cure. But if the district from which the sheep come is suspected, all diseases of the feet must be examined more cautiously than usual. A heat in the foot is a certain sign of an abscess existing in the hoof, to which an outlet should be given. The animal must then be carefully separated from the rest, and the operation performed which I am about to describe.

If the ulceration is visible, the place must be cleaned with a rag, and Goulard-water laid upon the sore by means of a feather, or the powder of blue vitriol. In order to prevent any dirt, \&c. from getting into the wound, the diseased foot should be placed in a little boot, the sole of which is of leather or felt, and the upper part of cloth, in order to fasten it round the leg of the sheep. This precaution is not only favourable to the animal; it also prevents contagion, which seems to be communicated by the pus or sanies which flows from the ulcers upon the litter of the sheep-fold. But when the disease is situated between the division of the hoof, the boot must be large enough to allow the foot to be moved in its natural way; for, if the two divisions were locked together, the disease would fester instead of healing. 
When the disease is seated within the horn of the hoof, it is attended with great pain without any visible disease; the animal does not rest upon the diseased leg, yet it has all the appearance of being well. Upon putting the hand upon the hoof it is found to be very hot; which is easily ascerained by comparing it with the sound legs. We must then endeavour to discover on what side the abscess or interior ulcer is : in order to do this, the foot of the animal must be slightly pressed with the thumb all round the junction of the horn with the skin, as well as the sole of the foot. The seat of the abscess may be easily ascertained by the wincing motion of the foot. This is the place which must be cut with a keen-edged knife, so as to occasion the discharge of the matter and lay the flesh bare. When the wound has bled for some time, a feather, wet with the water of Goulard, is laid upon it, and the boot above described is put on.

It sometimes happens, that upon pressing the foot with the finger no place can be fixed upon as being the seat of the disease : this is the case when the abscess is seated below the thickest and hardest place of the hoof. In this case it is necessary to make large incisions, sometimes without any benefit, before finding the disease; and after waiting a day or two the matter of the ulcer begins to appear, and eat 3 through the horn, in descending to the sole, which then becomes painfal at the place where it is necessary to make the incision.

In general we need not be afraid of cutting into the quick and bleeding the diseased feet. The horn of the hoof grows again with singular expedition. I have often seen feet which were completely unhoofed; others, of which part only of the horn was taken away, which healed much sooner than such feet as were scarcely ulcerated.

It would seem that in this disease, the juices which administer to the reproduction of the horn or hoof exist in greater abundance in the above places in disease than in health. When the disease is neglected, and where the sole of the foot has been gnawed off and the whole foot ulcerated, I often found that the sides of the horn had sent out cross 
slips from one side of the sole to the other, thereby becoming a sort of $\mathrm{boo}^{+}$, on which the animal rested without much pain. Sometimes also the horn in growing again assumes uncommon shapes.

The dressing must be carefully repeated every day with the greatest regularity. It consists in removing the boot and cleaning the wound with Goulard-water. The other feet of the animal must be examined as well as the diseased one; for the disease often passes from one foot to another, and it is sometimes visible to the eye before the animal is lame in the foot recently attacked. Some drops of Goulard-water will then prevent the progress of the disease. When the disease is taken in time, five or six days are sufficient for the cure. If a good deal of the horn has been removed it will require a longer time, until the horn has grown again, and assumed sufficient consistence for the animal to walk without being crippled.

As long as the least matter is perceived and the wound is not dry and cicatrized, even although the animal is not lame, it must not be thought cured, for it will carry back the contagion to the flock from which it had been separated. It must not be allowed to pasture with the rest until completely healed, and even then all its four feet ought to be bathed with vinegar fur a few days at first.

Unfortunately this malady is subject to frequent returns. I have often seen animals which appeared to be well cured and walked perfectly well for fifteen days, and then were again seized. Those which have already had it, so far from being less subject to it, are more exposed to it. This happens from the nature of the treatment. The remedies $I$ have prescribed can only check the progress of the disease; and until we have discovered a purifying specific, we may often see the disease reappear several times on the same animal.

It is of great consequence to be extremely vigilant in placing the animals in the infirmary, and in taking them away in proper time. In the season when sheep do not leave the fold, the lame ones are not easily discovered, and sometimes not until the disease is of some days standing, 
so that the disease may have been communicated to many others before the diseased animal is taken away.

If the least degree of infection is supposed to exist, they ought to be walked up and down every day in an inclosure, in order to observe if any of them are lame. It is also ne. cessary to remove them from the infirmary as soon as the ulceration disappears, because they may take the disease again from those around them. Fumigations of nitric acid are salutary for preventing the smell, and may also hasten the cure of the ulcers. The litter should also be frequently changed; and when removed it must not be left in a place where the heaithy animals are liable to be exposed to it.

When the precautions are resorted to, and the care taken which I have described, there will be no danger that the disease will assume any serious appearance.

Every thing pertaining to the knowledge of this disease, which is absolutely new in France, and I have reason to believe unknown in Spain, is extremely important to the proprietors of flocks of Merinos or mongrels. I hope that those who are in possession of any new facts on the subject of the foot-rot will publish them. I obtained from a professional man of Piedmont a succinct memoir concerning this disease, and I shall here insert it.

"Sheep, and particularly those with the finest wool, are subject to a contagious whitlow, which hinders them from pasturing, and which, on account of the pain and the suppuration which it occasions, gives them a continual fever, which increases in the evening. They fall off in flesh, and lose their wool; the rams lose the appetite for copulation, the mothers lose their milk, the lambs are weak and die of consumption.

"6 There are three kinds of whitlow, which succeed each other. The first is seated under the epidermis, between the two divisions of the foot; the animal is seen to halt : if we lay hold of the foot it feels hotter than usual, and it has a bad smell. Upon examining the place, an oozing out of matter is discovered.

"The second species of whitlow is seated under the horn. 
In this case the lameness and the heat of the foot are greater, as also the degree of fever.

"The third species attacks the phalanges or the bones of the foot, and is caused by inattention to the two former stages of the disease. The cure of this last is very troublesome and difficult.

"The disease arises from long journéys, pasturing in marshy places, allowing the sheep to mix with swine, or from lying in damp folds without litter.

"Preventatives.--1st, Remove as much as possible the above causes: 2d, separate the diseased from the healthy animals the instant the infection appears.

"Cure for the first stage of the complaint.-As soon as the shepherd perceives the disease, he must dry the place affected very carefully with a linen rag, and spread over it vitriol of copper in powder.

"In the second species of the whitlow, it is necessary to cut off that part of the horn which is detached from the phalange. We should begin cutting at the point of the horn and proceeding upwards. This operation must be performed by paring successively thin slips off the horn; when the horn is completely removed and the flesh bare, the receptacle of contagious matter is discovered. Sometimes it has gnawed very deep, and then the ulcer must be cleaned to the very bottom, by continuing to cut by little and little.

"In order to clean the wound thus laid bare, the foot must be plunged into water heated to such a degree that we can scarcely hold the hand in it. The diseased foot must be plunged and replunged in this hot water several times, letting it remain only a few seconds at each time in the water. It is then dried with a cloth, and a feather dipped in muriatic acid is drawn over the place. The animal must be kept in a fold where there is plenty of straw for 24 hours. Next day it may be put out to pasture where there are no stones nor thorns. Every night the feet of the animals must be inspected; and if ulcers are again formed the treatment must be renewed. They must be always dressed in the evenings, because the repose during the night greatly contributes to the good effects of the remedies. 
"The whitlow of the third species is very difficult to cure: the horn must be cut, and the flesh taken off also; and the carious bone must be then scraped, and seared with a red-hot iron."

The manner of operating with the knife, in order to discover the seat of the disease, is extremely well described in the above memoir. The analogy between the treatment of the whitlow in human creatures and that in animals, shows how efficacious the immersion in hot water is as recommended by the author; and the careful cleaning of the ulcers, upon which he insists, is extremely important. I entreat that some intelligent agriculturists may communicate to the public their observations from time to time on this disease, and the best methods of eure.

XXXVI. On two Species of the Sphex or Wasp, found in Virginia and Pennsylvania, and probably existing through all the United States. By H. Latrobe, Esq.

$\mathrm{T}_{\mathrm{H}}$ HE two species of sphex whose astonishing industry presents such interesting particulars, are known in America by the names of the blue wasp, the mason and the dirt-dauber. These wasps are distinguished among all the remarkable insects which belong to the order of the hymenopterce of Linnæus, by the singular and cruel manner in which they provide for their young.

The two species of sphex now mentioned are distinguished from each other by their manner of building, and by the form of their bodies; but they are quite similar in their manners, in the materials they employ in making their cells, and in the food they prepare for their progeny.

The first is probably the sphex ccerulea alis fuscis of Linnæus*. It is by far the most common: its feelers are sharp-pointed, and are extended when the insect is at work; on its snout it carries a strong beak, with which it works sideways, by making furrows on the surface of its little

* The blue ichneumon wasp, with gilt wings. (De Geer.) 